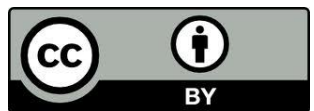

\title{
A busca por um lugar do Ensino Religioso na escola pública através da interdisciplinaridade
}

\author{
The search for a place of religious education in public schools through the \\ interdisciplinarity
}

\author{
Matheus Oliva da Costa \\ Graduado em Ciências da Religião (Unimontes); \\ Mestrando em Ciência da Religião (PUC-SP) \\ matheusskt@hotmail.com
}

RESUMO: A interdisciplinaridade é uma chave para uma legitimação do Ensino Religioso (ER) na Educação Básica em escolas públicas. É exatamente isso que concluí-se neste paper. O objetivo aqui é propor uma legitimação do ER através de uma metodologia interdisciplinar. A falta de diretrizes para essa disciplina - em âmbito nacional e na maioria dos estados - assim como uma breve observação da sua situação nas escolas demonstra o descaso para com o ER nas escolas públicas no Brasil. Enquanto graduado em Ciências da Religião e professor de ER em Belo Horizonte (MG), o presente pesquisador pretende mostrar, a partir de suas avaliações do primeiro bimestre de 2013, como a interdisciplinaridade é um caminho interessante a um status de legitimidade ao ER. Isso, tanto para o poder público como para a comunidade escolar. As avaliações interdisciplinares são uma expressão de uma interação com conteúdos e com as(os) professoras(es) de outras disciplinas. Essa interação mostrou-se como ferramenta didática e metodológica que proporciona cientificidade ao ER, e, consequentemente, aceitação e sentido para essa disciplina.

Palavras-chave: Interdisciplinar; Escola pública; Ensino Religioso.

ABSTRACT: Interdisciplinarity is a key to a legitimization Religious Education (RE) in Basic Education in public schools. That's exactly what it was concluded that paper. The goal here is to propose a legitimation of ER through an interdisciplinary approach. The lack of guidelines for this course - nationally and in most states - as well as a brief observation of their situation in schools shows contempt for the RE in public schools in Brazil. While a degree in Religious Studies and professor of ER in Belo Horizonte (MG), this research aims to show from their evaluations of the first two months of 2013, as interdisciplinarity is an interesting path to a status of legitimacy to the ER. Therefore, both the government and the community school. Interdisciplinary assessments are an expression of an interaction with content and with (the) teachers (es) of other disciplines. This interaction was shown as a teaching tool and methodology that provides scientific to the ER, and therefore acceptance and sense to this discipline.

Keywords: Interdisciplinary, Public School, Religious Education. 


\section{A realidade do Ensino Religioso no Brasil e em Minas Gerais}

O presente paper não objetiva mostrar uma história do Ensino Religioso (ER) no Brasil, ou mesmo em Belo Horizonte - MG, local onde aconteceram as experiências educativas relatadas aqui. Felizmente já temos autores que trataram da história do ER no Brasil e alguns dos seus estados, direta ou indiretamente. Por exemplo: Anísia de Paula Figueiredo (1999), Sergio Junqueira (2002, 2011), Giseli do Prado Siqueira (2003), João Décio Passos (2007), Lurdes Caron (2007), Debora Diniz (2010) e claro, o Fórum Nacional Permanente do Ensino Religioso - Fonaper (2009) formado por diversos autores.

Ainda em âmbito nacional, pontuamos somente que existe uma ausência de diretrizes claras sobre o ER, e muito menos há um livro didático oficial. Existe, no entanto, o artigo 33 da LDB, alterado em 1997 pela Lei 9.457. No que concerne ao conteúdo e ao objetivo do ER, o texto do art.33 da LDB afirma que nessa disciplina deve ser "assegurado o respeito à diversidade cultural religiosa do Brasil, vedadas quaisquer formas de proselitismo", sendo parte integrante da formação cidadã. Temos então três pontos chaves a serem lembrados neste documento norteador para o ER: 1) o conteúdo e o objetivo geral da disciplina devem contemplar a visibilidade e respeito da diversidade religiosa brasileira; 2) É proibido qualquer proselitismo, ou seja, propagandas ou indução por parte do docente de quaisquer crenças religiosas; e 3) os dois pontos anteriores norteiam o ER de forma que este contribua para a formação do cidadão de um Estado Democrático de Direito, e não de um religioso.

Em Minas Gerais, seguindo os rumos do Brasil, observamos a ausência de diretrizes claras ao ER. Existem, no entanto, dois documentos oficiais em Minas sobre o ER: 1) a Lei 15434/2005, regulamentada pelo Decreto n. 44.138 de 2005 (Diniz et al, 2010), dispõe sobre a disciplina, mas segue as orientações da LDB com pequenos acréscimos - o licenciado em Ciências da Religião é o profissional habilitado a docência, e afirma a necessidade de fundamentação em disciplinas como antropologia cultural; 2) O Guia de orientação curricular (versão preliminar) criado em 2009 pelo projeto “Acelerar para vencer" (PAV), da Secretaria Estadual de Educação, escrito para um público de estudantes que tem dificuldades para concluir os ciclos escolares. Ressalto, ainda, que na tentativa de estabelecer um currículo para o ER, além de mostrar 
falta de embasamento científico, o termo "ciências das religiões" (SEE-MG, 2009, p.46) aparece de forma avulsa e descontextualizada, demonstrando certa ignorância com a proposta da Ciência da Religião para com o ER.

Até mesmo a história do ER não foi escrita de modo satisfatório em Minas. Existem algumas exceções de trabalhos que abordam questões locais, como o pesquisador Douglas Cabral Dantas (2002). Em sua dissertação Dantas (2002, p.73 a 83) mostra como o ER - em escolas públicas da rede estadual em Belo Horizonte - é historicamente tratado de forma negativamente diferenciada, e sofre total influência das igrejas cristãs, em especial da Igreja Católica Apostólica Romana (ICAR). Por outro lado, este pesquisador apontou as várias tentativas de mudar este quadro por parte de associações de igrejas cristãs e do próprio governo, especialmente após a LDB (1996/1997). No que concerne a presença da ICAR no ER de Minas, citamos o seguinte comentário de Passos (2007, p.92) sobre o quadro geral do ER no Brasil:

Parece haver, em termos weberianos, uma afinidade eletiva entre os interesses cristalizados do Estado (autonomia se suas instituições, inclusive a instituição chamada ciência) e os das Igrejas (de divulgação de suas doutrinas). O ER fica refém dessa confluência de posturas apologéticas que, do ponto de vista histórico, é mais simples e cômodo conservar do que mudar.

E não somente Passos (2007) percebeu a forte proximidade que as igrejas têm com o ER, Debora Diniz (et al, 2010) também atinou para a situação. Diniz (2010) afirma que a laicidade existe no estado brasileiro através de uma pluriconfessionalidade, ou seja, não é regulado oficialmente por nenhuma religião, mas sofre forte influência das confissões religiosas, especialmente cristãs. (Diniz et al, 2010, p.23). Ainda afirma que há duas hipóteses explicativas sobre a situação que se encontra o ER religioso no Brasil: 1) a crença social da anterioridade do fato religioso na sociedade brasileira, e 2) a concepção comum de que religião é assunto de religiosos quase exclusivamente. Tanto Passos (2007) como Diniz (2010) denunciam a situação confusa do ER, além de apontarem para o desrespeito a laicidade da atual República Federativa do Brasil como pano de fundo deste cenário.

Existem, ainda, outros trabalhos que abordam o ER em Minas Gerais. Há vários trabalhos produzidos - monografias e artigos - por estudantes do curso de Ciências da Religião da Universidade Estadual de Montes Claros - UNIMONTES. Dentre eles: A 
percepção de educandos (Crianças e Adolescentes) sobre a Educação Religiosa em escolas da educação básica do Norte de Minas (Vianna et al, 2011) escrito por pesquisadores que cursavam o curso citado. Mesmo que produzidos apenas por graduandos, com algumas exceções de trabalhos esporádicos sobre ER pelos professores, essas produções acadêmicas são fruto de uma tentativa de construção de um ER laico fundamentado nas Ciências da Religião ${ }^{1}$ em Minas Gerais.

\section{Consequências do desamparo ao Ensino Religioso}

Essa situação do ER no Brasil e em Minas Gerais pode gerar todo tipo de maus entendidos, autoritarismos, desvalorização social e até descasos para com a disciplina em questão. Exemplo bem visível disso é a situação do ER em relação a Resolução 666 de 2005 da Secretaria Estadual de Educação de Minas Gerais. Com essa resolução iniciou-se a construção de CBC's (Conteúdo Básico Comum) para as disciplinas das séries finais do ensino fundamental e do ensino médio. Mas o ER foi a única disciplina que não foi contemplada neste processo, demonstrando o tratamento desigual com a disciplina.

Em uma perspectiva de dentro, enquanto professor da rede de educação estadual de Minas Gerais entre os anos de 2012 e 2013 pode-se dizer que essa situação de ausência de diretrizes e descaso pode alavancar muitos problemas. Tais entraves atingem todos que estão envolvidos na comunidade escolar: professores, estudantes, diretoria, equipe pedagógica, secretaria de educação, pais/responsáveis e até auxiliares de serviços gerais. Citamos alguns danos que podem ocorrer, gerados por tal situação caótica:

- Falta de objetividade do trabalho docente, dificultando sua atuação;

- Deslocamento ou estranhamento no ambiente de trabalho, onde o docente é muitas vezes excluído de cursos, capacitações, chegando a ser esquecido em certas situações do cotidiano escolar;

- Favorece confessionalismos religiosos, ou seja, catequeses dentro da escola laica, tanto pelos professores como pelas pedagogas;

- Confusão e ambiguidades sobre a natureza do Ensino Religioso, principalmente por parte da equipe pedagógica;

- Conflitos relativos ao papel dessa disciplina em escolas públicas e laicas também em relação à equipe pedagógica;

${ }^{1}$ Ciências da Religião é a denominação utilizada no curso da Unimontes. 
- Falta de clareza por parte dos educandos em relação ao motivo de estudarem essa disciplina, causando aversões munidas de preconceitos, ou mesmo um descaso excessivo (lembrando que nessa disciplina não tem a possibilidade de reprovação, todos e todas devem concluir o ano escolar sendo aprovados);

- Pode criar conflitos entre a equipe pedagógica, diretoria, professores, educandos, ou até mesmo com os trabalhadores auxiliares de serviço geral, já que cada um deles vai defender uma forma correta de ER;

- Ao favorecer confessionalismos cria tensões entre pais e professores, uma vez que há uma pluralidade de confissões religiosas no ambiente escolar, e a escola pode se tornar um espaço de disputa religiosa.

Deve ser levado em conta que muitas dessas situações podem ocorrer em ambiente escolar - e muitas ocorreram com o autor deste trabalho, ou foram observadas em seus estágios acadêmicos. Destarte, é urgente a regulamentação do ER nas escolas públicas, em todos os aspectos necessários: formação docente, legislações mais específicas, preparação da comunidade escolar, diretrizes epistemológicas, definição de conteúdo e objetos, modelos metodológicos, e material didático. Seguindo a terminologia de Sergio Junqueira (2011) trata-se de prosseguir no caminho de escolarização do ER.

A urgência pela escolarização da disciplina Ensino Religioso

Na trilha do processo de escolarização do ER, o presente trabalho segue o pressuposto de dois cientistas da religião brasileiros (Passos, 2007 e Soares, 2010) de que o ER deve ser a transposição didática da Ciência da Religião. "Portanto, os temas das Ciências da Religião deverão ser traduzidos para os do ER", afirma João Décio Passos (2007). Ou seja, o estudo científico das religiões deve ser adaptado e traduzido aos anos do ensino fundamental (e médio, quando for o caso). Visando esclarecer mais a questão, utilizamos aqui a seguinte conceituação do que seria a transposição didática:

A Transposição Didática é um "instrumento" pelo qual analisamos o movimento do saber sábio (aquele que os cientistas descobrem) para o saber a ensinar (aquele que está nos livros didáticos) e, por este, ao saber ensinado (aquele que realmente acontece em sala de aula). O termo foi introduzido em 1975 pelo sociólogo Michel Verret e rediscutido por Yves Chevallard em 1985 em seu livro La Transposition Didactique, onde mostra as transposições que um saber sofre quando passa do campo 
científico para o campo escolar. Chevallard conceitua "Transposição Didática" como o trabalho de fabricar um objeto de ensino, ou seja, fazer um objeto de saber produzido pelo "sábio" (o cientista) ser objeto do saber escolar. (Polidoro e Stigar, 2010, p.1 e 2)

Antes de chegar a essa conclusão, primeiramente Passos (2007) propôs que existem três modelos de ER: confessional/catequético, teológico/ecunêmico e da Ciência da Religião. Afonso Maria L. Soares (2010), em concordância com a tipologia proposta por Passos (2007), reafirma a tese deste último de que “[...] a Ciência da Religião é o modelo mais coerente para fundamentar teórica e metodologicamente a prática do Ensino Religioso" (Soares, 2010, p.140). Afirma, mesmo, que "[...] a Ciência da Religião como base epistemológica e, portanto, como área de conhecimento pertinente ao Ensino Religioso [...]" é a melhor forma de estabelecer uma educação condizente com a proposta atual de educação, focada na aprendizagem do estudante e que valoriza a pluralidade cultural brasileira. Mais recentemente, também Sérgio Junqueira (2011, p.182) explicitou que está de acordo com tal proposta.

Neste paper, há também a ousadia de afirmar que o modelo da Ciência da Religião ao ER proporciona justiça religiosa e consequentemente respeito entre religiosos(as). Mas o que é justiça religiosa? Segundo Diniz (et al, 2010, p.29) "a justiça religiosa é um dos princípios básicos para a promoção da cultura dos direitos humanos", onde todas as confissões religiosas tem um espaço igualitário para se expressar dentro de um espaço laico. Indo em combate a intolerância religiosa e estando de acordo com o respeito mútuo entre as religiões e a promoção da laicidade e dos direitos humanos, assumi-se aqui que o modelo que a Ciência da Religião propõe ao ER é o mais adequado à realidade brasileira, promovendo a justiça religiosa também em sala de aula. Sendo a transposição dos estudos científicos sobre as expressões religiosas, contribui em muitos pontos com os objetivos acima propostos.

Passos (2007, p.105 a 110) chegou a enumerar os motivos para a implementação do modelo da Ciência da Religião ao ER: 1) Como estudo das religiões, dissipando a ignorância e preconceito ao outro; 2) Como interpretação da realidade, ajudando os discentes a compreender as culturas como universo simbólico próprio dos seres humanos; 3) Como religação dos conhecimentos, promovendo a interdisciplinaridade e combatendo a especialização radical, já que a própria Ciência da Religião é 
interdisciplinar; 4) Como formação do ser humano, sendo elemento de conscientização que situa o estudante como ser humano que é biológico, mas também faz parte de uma realidade sociocultural; 5) Como convivência social como o outro, construindo uma cultura de respeito a diversidade; e 6) Como parâmetro ético, embasado numa proposta de conviver respeitosamente com o diferente.

Ressalta-se que mundialmente a Ciência da Religião adquiriu um "caráter multidisciplinar" para seus estudos, onde cada contribuição está interessada "em todas as dimensões que compõem qualquer religião concreta", segundo Frank Usarski (2006, p.43). Podemos afirmar que o termo multidisciplinar está intencionalmente próximo de interdisciplinar, como pode ser visto nos textos de Passos (2007) e Soares (2010), sendo os três autores citados acima docentes de um mesmo programa de pós-graduação em Ciências da Religião, na PUC-SP. Nesse sentido, propõe-se que metodologicamente o ER deve-se nortear por um princípio interdisciplinar, enquanto transposição didática da Ciência da Religião. Agora, segue uma sugestão de como isso pode ser feito.

Interdisciplinaridade, Ciência da Religião e Ensino Religioso

Tanto Passos (2007, p.106), quanto a doutora em educação Olga Pombo (2005) deixam claro que termos como multidisciplinaridade, pluridisciplinaridade, interdisciplinaridade e até transdisciplinaridade apontam para algo além da simples disciplina, sendo "[...] em todos os casos, uma tentativa de romper o carácter estanque das disciplinas." (Pombo, 2005, p.3). Há, então, certa relutância em aceitar a demasiada especialização dos saberes, apontando para os problemas que uma separação radical das ciências pode gerar, ou melhor, secar a própria ciência.

Segundo Olga Pombo $(2005$, p.8) “[...] o todo não é a soma das partes. Esta é, penso eu, uma das chaves fundamentais para o entendimento [...]" da interdisciplinaridade. Partindo dessa assertiva, reflete-se que a epistemologia atual começou a perceber que existe uma frutífera interação entre os olhares das várias ciências. E o ditado se faz valer: um ponto de vista é sempre a vista de um ponto. A Ciência da Religião, em sua fase mais madura percebeu essa rica possibilidade de utilizar diferentes áreas científicas para o estudo do seu objeto - as expressões religiosas - favorecendo uma interação entre disciplinas que estudam as religiões. Dessa forma, 
uma Ciência da Religião, além de empírica, deve ter disponível diversas lentes para ler as expressões religiosas (Usarski, 2006). Esse é, justamente, o que a leitura do livro $O$ espectro disciplinar da ciência da religião (org. de Frank Usarski, 2007) demonstra ao leitor.

Enquanto professor da rede estadual de educação de Minas Gerais observa-se que os docentes das escolas públicas não tem tempo, incentivo, preparação ou (por vezes) disposição para um trabalho interdisciplinar. $\mathrm{Na}$ verdade, a estrutura e organização das escolas públicas não facilitam essa interação. Nesse sentido, sendo o ER uma transposição didática da Ciência da Religião, uma forma de solucionar algumas barreiras ao ER em escolas públicas - como as expostas anteriormente - é, exatamente, fomentando o trabalho interdisciplinar. Todavia, a interdisciplinaridade não é apenas uma interação intelectual:

[...] a interdisciplinaridade se deixa pensar, não apenas na sua faceta cognitiva - sensibilidade à complexidade, capacidade para procurar mecanismos comuns, atenção a estruturas profundas que possam articular o que aparentemente não é articulável mas também em termos de atitude - curiosidade, abertura de espírito, gosto pela colaboração, pela cooperação, pelo trabalho em comum.” (Pombo, 2005, p.11)

Dessa forma, uma atitude interdisciplinar está de acordo com o modelo de ER da Ciência da Religião proposta por Passos (2007) e reafirmada por Soares (2010) e Junqueira (2011). Também pode ser um elemento legitimador do ER nas escolas públicas, contribuindo com o processo de escolarização da disciplina. Em alguns trabalhos desenvolvidos a partir dessa atitude, na Escola Estadual Deputado Álvaro Salles, localizada no bairro Trevo da cidade de Belo Horizonte, o autor que vos escreve observou resultados bastante favoráveis ao reconhecimento dessa disciplina ER por toda comunidade escolar, ajudando a romper os entraves que existem para sua escolarização. Mas, antes de mostrar os resultados, vamos ao relato de experiência propriamente dito.

Logo após a conclusão do curso em Ciências da Religião da Unimontes em 2012, o presente pesquisador imediatamente começou a ministrar aulas de ER em escolas públicas da rede estadual de educação de Minas Gerais, na cidade de Belo Horizonte. Durante este período, muito foi pensado em relação a prática de um ensino religioso laico, que seja a transposição didática da Ciência da Religião e siga a LDB (em 
especial o art.33). Apesar da realidade maçante das escolas públicas de Minas - com baixos salários, pressões políticas constantes, e uma educação em crise onde a relação professor-aluno está comprometida moralmente - foi um momento interessante, onde foi possível aplicar as lições aprendidas na graduação, com erros e acertos.

Contudo, nos primeiros meses de trabalho não foi possível desenvolver muitos trabalhos interdisciplinares da parte do docente em ER que vos escreve, por vários motivos. Foi somente em 2013, trabalhando na Escola Estadual Deputado Álvaro Salles que experiências interdisciplinares surgiram de forma mais significativa. A escola, localizada no bairro Trevo, região da Pampulha em Belo Horizonte, apresenta um público misto economicamente falando, vindos de diversas realidades sociais, mas sempre de bairros próximos à escola.

No quesito religião a situação é mais específica: em um questionário informal aplicado na primeira aula do ano, os estudantes informaram suas confissões religiosas: das treze (13) turmas presentes no turno matutino, doze (12) tem uma predominância numérica da autodenominação geral de evangélicos; Há também, obviamente, uma forte presença católica entre os discentes, ficando em segundo lugar. Em todos os anos $\left(6^{\circ}\right.$, $7^{\circ}, 8^{\circ}$ e $9^{\circ}$ anos) há cerca de 1 a 2 estudantes "sem religião" em cada turma; Há ainda uma denominação genérica de espíritas, a julgar pelos própios estudantes, podendo incluir desde kardecistas, umbandistas ou candomblecistas, contando com três (3) ao todo que se autodenominaram. Estes números, claro, são aproximativos, uma vez não se tratou de uma pesquisa oficial. Também a veracidade das respostas é questionável, podendo variar já que nem sempre adolescentes entre 11 e 14 anos sabem dizer claramente o que seria uma religião (Vianna et al, 2011).

Uma vez contextualizada a situação dos discentes, vamos a questão da atitude interdisciplinar (Pompo, 2005) dos docentes e equipe pedagógica. Entende-se aqui duas formas de se fazer interdisciplinaridade (sem descartar a possibilidade de outras): 1) usando de conteúdos, metodologia, ou mesmo uma comparação sistemática e avaliativa de outra(s) disciplina(s) para desenvolver um tópico da sua própria disciplina - no caso, ER; e 2) um trabalho conjunto entre dois ou mais professores, onde ambos trabalham com o mesmo tema/tópico em suas aulas, mas com uma abordagem ligada a sua própria disciplina. Nesse último caso, há interdisciplinaridade, por que um mesmo objeto de ensino é visto por dois ângulos simultaneamente e de forma mutuamente complementar, 
ampliando o processo de ensino-aprendizagem dos discentes. Cabe lembrar que a equipe pedagógica apoiou e incentivou o trabalho conjunto, contribuindo para a fluência da proposta. Vamos ver então mais detalhadamente como cada um desses casos foi realizado nas salas de aula da escola supracitada.

\section{Avaliação interdisciplinar por comparação sistemática de conteúdos}

Uma vez que, historicamente, as aulas de ER não estavam munidas de um conteúdo científico ou histórico, foi necessário tomar uma decisão: como começar a falar de religião, um assunto tão polêmico? Decidi ${ }^{2}$ que seria através de uma base histórica, mas principalmente, sociocultural. Afinal, além de ser uma possibilidade interessante de entender as expressões religiosas da humanidade, enquanto transposição didática, o ER deve seguir a Ciência da Religião contemporânea, que está localizada como uma Ciência Cultural (Hock, 2010). Desde o estágio acadêmico (Vianna et al, 2011) já foi percebido que estudantes do $6^{\circ}$ ano (10 a 11 anos de idade) ainda não estão desenvolvidos plenamente em seu estágio cognitivo para entender o conceito de religião, e, por consequência, o de cultura. Sendo assim, foi decidido que estudantes dos $7^{\circ}, 8^{\circ}$ e $9^{\circ}$ anos teriam uma introdução aos estudos culturais, e por fim, no próprio conceito de religião enquanto uma expressão cultural.

A aplicação desde método sequencial de estudos no ER (entender: cultura $\rightarrow$ religião) se mostrou bastante sólido desde o início da trajetória docente profissional do presente autor, já em 2012. Durante o exercício dessa experiência pedagógica em uma das aulas de ER para os $7^{\circ} \mathrm{s}$ anos da E.E. Dep. Álvaro Salles, houve uma recepção inesperada. Em meados de março, eu explicava (baseado em Durkheim, 1996) como as religiões são sistemas culturais de crenças e ritos, centrados em um sagrado também construído socialmente, quando então, um estudante questionou: "é igual ao sistema solar, professor?".

Mesmo sem lembrar quem foi, ou mesmo em qual $7^{\circ}$ ano isso aconteceu, este momento gerou um insight que até hoje me é bem vivido. No mesmo momento as ideias fluíram em sala de aula tanto pelo docente como pelos(as) discentes. Desenhei então um sistema solar no quadro e solicitei a atenção e colaboração de todos(as): "Vamos fazer

\footnotetext{
${ }^{2}$ A partir daqui, peço licença aos leitores e leitoras para usar a primeira pessoa do singular, entendendo que trata-se de um relato que parte de uma visão e experiência única do pesquisador.
} 
uma experiência: você, por favor, escolha uma religião que conhece!", responderam (sim, muitos juntos, estavam empolgados): "católico", outros falaram "evangélico". Usamos os dois exemplos. Vamos agora seguir com o exemplo dos evangélicos, para aprofundar o relato. Continuei perguntando: "Já que o sistema solar é centrado no sol, como o próprio nome diz, se compararmos esse sistema com a tradição dos evangélicos, qual seria o sol dos evangélicos?". Depois de uma rápida discussão, chegamos numa conclusão: "é [a crença em] Deus". Por fim, indaguei: “O que seria então os planetas da tradição evangélica? E as estrelas, que estão presentes em todo sistema solar, o que seria na tradição dos evangélicos?". Segue agora algumas das respostas: “os pastores, a bíblia, as igrejas e [sobre a última questão] os fiéis".

Passei a usar este exemplo em todas as turmas, e percebi que uma grande maioria dos discentes fazia uma conexão interessante com a ideia de religião como sistema cultural. Resolvi me inteirar com livros didáticos da disciplina Ciências, e percebi que em livros didáticos geralmente o sistema solar é um conteúdo ensinado nos $6^{\circ} \mathrm{s}$ anos do Ensino Fundamental. Quando chequei o CBC de Ciências da rede de educação de Minas Gerais percebi que o tópico 23, relacionado ao $6^{\circ}$ ano, também afirma que o tema "sistema solar" deve ser abordado ${ }^{3}$. Dessa forma, aproveitando as aulas sobre religião como sistema cultural nos $7^{\circ} \mathrm{s}$ anos, foi criada uma avaliação bimestral (exigida pela SEE-MG nas escolas) para os discentes.

$\mathrm{Na}$ avaliação busquei fazer com que o estudante faça uma conexão entre um conteúdo estudado e possivelmente consolidado - o sistema solar - e uma nova informação a ser absorvida: um conceito sociocultural de religião. Foi percebido que os discentes entendem com maior facilidade o novo conteúdo a partir de uma comparação sistemática com outro que já conhecem. Somada ao conhecimento prévio que foi adquirido no ano anterior ( $6^{\circ}$ ano), a temática do funcionamento físico do universo em sua versão das ciências naturais parece ser um atrativo que faz vir à tona a atenção e a afeição dos educandos. Sabe-se (Vianna, et al, 2011) que a afetividade é um importante elemento na construção do saber do educando, sendo um alicerce do processo de ensino-aprendizagem.

\footnotetext{
3 Temos, ainda, um tópico bem especifico sobre a questão presente no CBC de Ciências (SEE-MG): "23.2. Diferenciar os modelos geocêntrico e heliocêntrico do Universo e reconhecê-los como modelos criados a partir de referenciais diferentes.", mesmo que esta habilidade básica (e subtópico) seja direcionado aos $8^{\circ} \mathrm{s}$ anos.
} 
Para adolescentes da faixa etária de 12 e 13 anos, conceitos de cultura e religião ainda são abstratos. Assim, por ainda necessitarem de exemplos materiais, bem como para manter um nível empírico de entendimento, optei por um exemplo específico de tradição religiosa na avaliação bimestral: a tradição cristã, pois é mais próxima do cotidiano dos estudantes. Obviamente os conceitos de tradição (cultural), de cultura e de religião foram trabalhados previamente através de aulas expositivas, avaliações formativas (com exercícios em cada subtópico ensinado), pesquisas individuais e debates em sala de aula.

Mas, se por um lado ainda há limitações cognitivas, os discentes do $7^{\circ}$ ano estão em plena fase de desenvolvimento. Estando localizados no terceiro $\left(3^{\circ}\right)$ ciclo do ensino fundamental, segundo os Parâmetros curriculares nacionais do Ensino Religioso da Fonaper (2009, p.73, grifo meu), afirma que se trata de um "período escolar em que o educando começa a aprender a pensar sobre coisas imaginárias e ocorrências possíveis, passando da lógica indutiva para a dedutiva (...)”. Ou seja, podemos começar algumas abstrações ou generalizações, com o devido cuidado, de forma que encoraja o desenvolvimento cognitivo. Segue agora uma avaliação bimestral respondida por uma estudante do $7^{\circ} \mathrm{ano}^{4}$ em 19/04/2013:

\footnotetext{
${ }^{4}$ Ocultamos o nome por escolha metodológica de preservar a identidade da discente.
} 


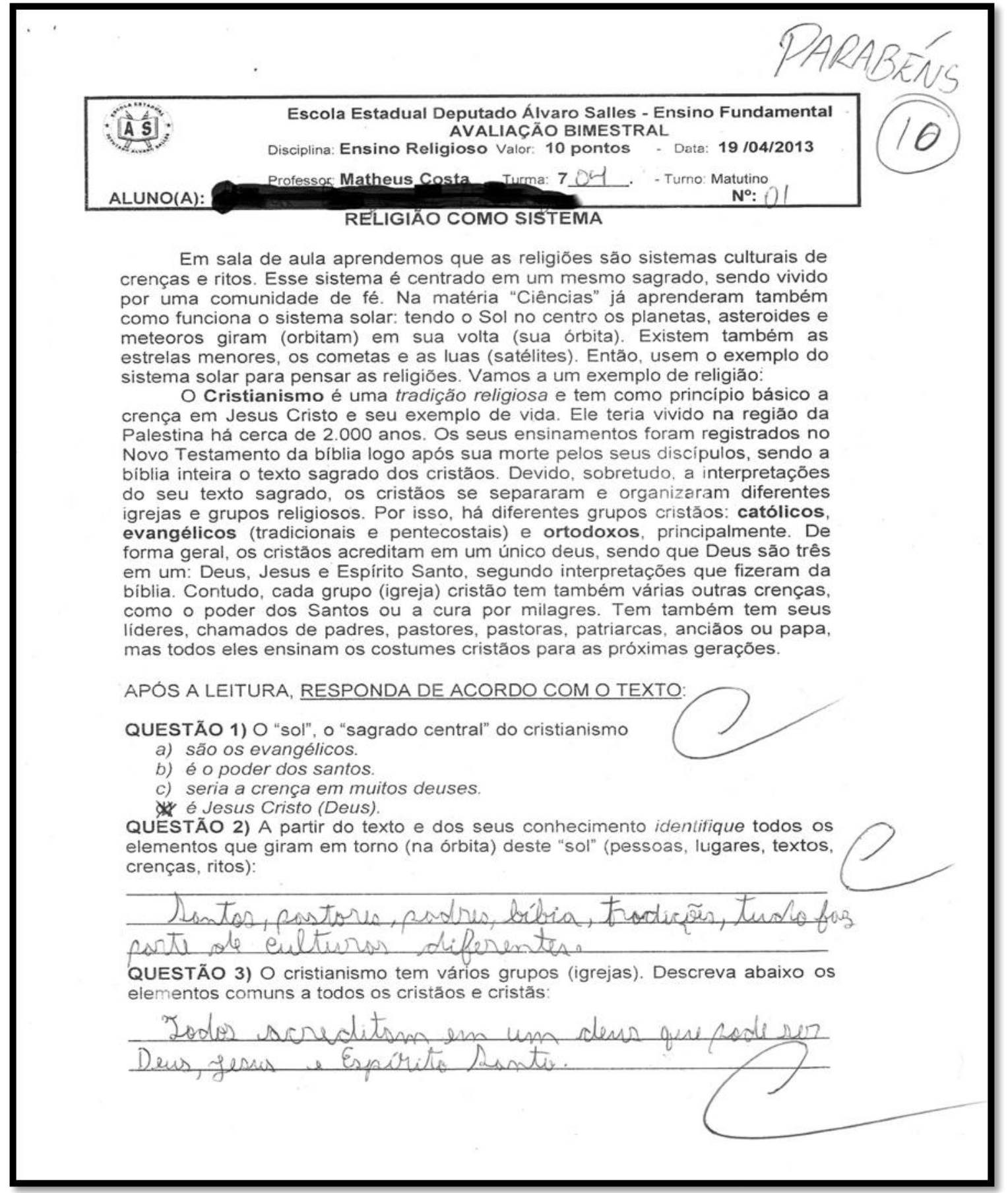


QUESTÃO 4) Escreva em cada parte da figura abaixo os elementos descritos na "questão 2", deixando o sagrado central no centro (sol):

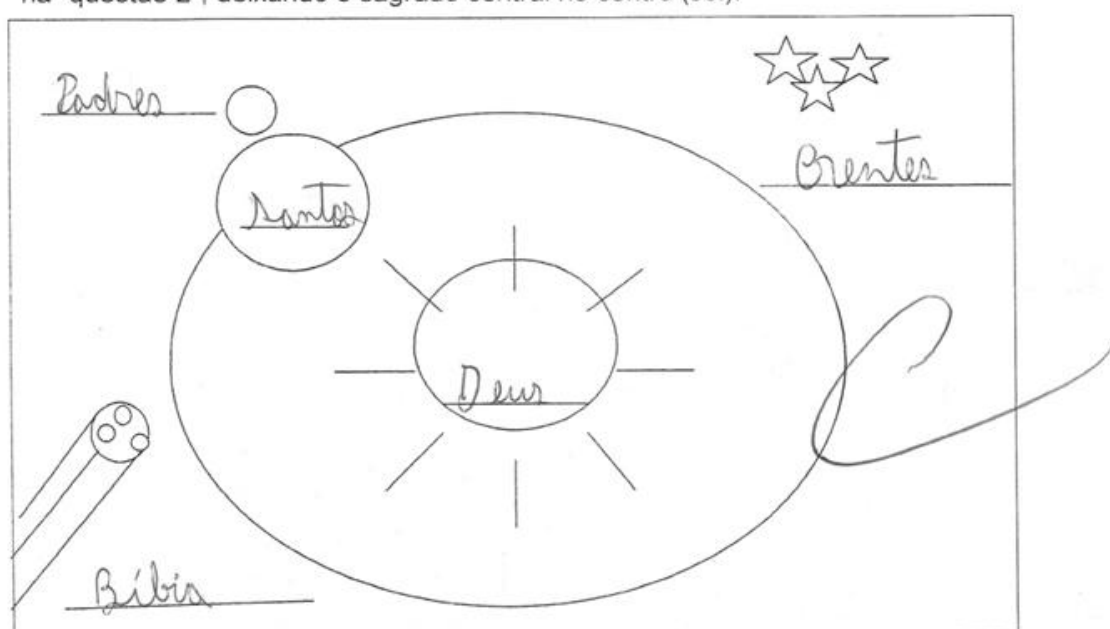

QUESTÃO 5) O principal motivo para a existência de muitos grupos diferentes

a) por que Jesus Cristo nasceu a muitos anos.

b) devido a seus ensinamentos serem passados de geraçăo em geração

- são a muitas interpretações que fazem do seu texto sagrado.

d) por que os seus lideres eram todos diferentes.

QUESTÄO 6) As religiöes tem muitos elementos, mas todos podem ser resumidos em dois: crenças e ritos. Os textos sagrados são

a) escritos somente sobre ritos religiosos.

x. registros das crenças das religiōes.

c) textos sem importância para as religiōes

d) somente Novo Testamento.

QUESTÃO 7) Explique em uma frase: qual é a principal mensagem, $\underline{0 \text { autor. }}$ onde e quando foi escrita a biblia:

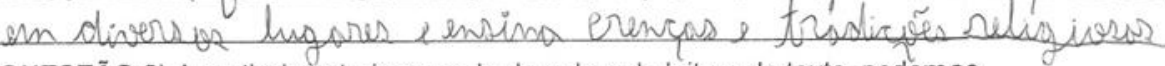

QUESTÃO 8) A partir do estudo em sala de aula e da leitura do texto, podemos inferir que os textos sagrados tem como objetivos

a) separar as religiōes em vários grupos religiosos.

b) criar vários lideres, cada um usando um texto.

c) ter uma única verdade, sem interpretações.

o. preservar e difundir as tradiçōes religiosas.

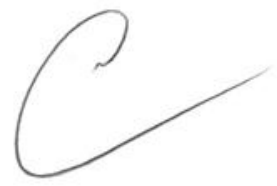

Boa prova!

"Aprender é aprender a fazer de si mesmo um ser humano" (Zhang Zai, séc. XI)

A avaliação acima abrangia também outro tema, textos sagrados, escolhido por influência do Caderno Pedagógico de Ensino Religioso - O Sagrado no Ensino Religioso produzido pela Secretaria estadual de educação do Paraná (2008). Contudo, não será debatido essa questão aqui, para não perder o foco. Ainda sobre a avaliação 
acima, pode-se perceber que as repostas da estudante demonstraram o desenvolvimento da habilidade de perceber a religião como um sistema cultural.

Na questão 2, por exemplo, usei termos próprios da sociologia da religião de Émile Durkheim (1996), como elementos (religiosos), para a leitura do objeto de estudo da avaliação: o cristianismo. Mas, fazendo valer a interdisciplinaridade, também foram usados termos próprios da temática da estrutura do sistema solar como órbita, sol $e$ planetas de forma comparativa com a terminologia da sociologia da religião durkheimiana como os conceitos de crenças e ritos. A questão 4 vai mais longe com a comparação com o sistema solar e as religiões, propondo que o educando posicione corretamente os elementos do cristianismo em um quadro aproximativo de um sistema solar.

Observem que enquanto as questões 2 e 4 seguem uma lógica mais tangível e empírica, onde a leitura e o conhecimento prévio do discente vai nortear a resposta, a questão 3 já aponta há uma necessidade de abstração e até de interpretação do texto. Assim, também foi exigida a capacidade de generalização e de imaginação, de forma que a resposta só era possível com uma leitura atenta e interpretativa do texto, mas tudo dentro do alcance cognitivo dos educandos. Dessa forma, exercitou-se o pensamento lógico dos educandos.

Avaliação interdisciplinar através de uma atitude interdisciplinar

A experiência com a interação entre o conteúdo de uma disciplina diferente dentro das aulas de ER foi bastante proveitosa e gerou bons frutos. Mas ainda sim é uma experiência limitada a visão de somente um docente. Agora será relatada uma frutífera relação interdisciplinar entre eu e o professor de História, Thiago de Castro Menta. Este professor, em meados do mês de março, certo dia me convidou a abordar o mundo grego para os estudantes dos $6^{\circ}$ anos. Conversamos sobre os objetivos dessa escolha, e o docente argumentou que entender a Grécia antiga era importante para que eles (os $6^{\circ}$ anos) pudessem entender melhor a sociedade atual, sendo que a Grécia é considerada o berço do que se entende por ocidente.

Esse convite me chegou em um ótimo momento, pois, após algumas experiências com o tema mito nas aulas de ER, percebi que era necessário aprofundar 
em alguma mitologia em especial, de forma que superasse uma superficialidade e o senso comum do assunto. Assim, foi possível o devido aprofundamento em uma estrutura de mitos de uma cultura em especial. Seguindo o entendimento antropológico de Gilbert Durand (2002), o mito deve ser entendido pelo próprio mito. Dessa forma, através de microcomparações entre diferentes mitos gregos, é possível compreender o sentido geral desses mitos enquanto uma grande estrutura simbólica, e ao mesmo tempo clareia o entendimento dos mitos mais específicos dessa cultura antiga.

Mas a própria escolha da temática mito merece uma explicação. Como pode ser lido em Vianna (et al, 2011), adolescentes de até 13 anos não entendem claramente o que seria religião. Como comprovam estudos empíricos de psicólogos e antropólogos, é a partir de 12 ou 13 anos de idade que a noção de religião vai aparecer. O que existe antes são ideias avulsas relacionadas à religiosidade, como a noção de algo sagrado (intocado, de extrema importância) ou a de um Deus (ao melhor, papai-do-céu). Antes dos treze anos segue-se certos ritos religiosos, como o costume religioso brasileiro de pedir benção, mas sem um entendimento específico quanto a uma (suposta) religiosidade do ato. Destarte, como já dito, conceitos como religião e cultura não devem ser trabalhados nos anos anteriores da faixa etária em questão, correspondendo ao $6^{\circ}$ ano e a anos anteriores.

O que deve ser estudado então nas aulas de ensino religioso, se não deve ser religião? Conceitos que atravessam o universo simbólico religioso podem servir de aporte ao professor de ER, como mito, símbolos, lugares sagrados, corporalidade (símbolos rituais) ou arte. Para o primeiro bimestre de 2013, escolhi os temas mitos e lugares sagrados para estudar aspectos da religiosidade que podem ser entendidos pelos educandos. Mas foi com o convite do professor de história das turmas dos $6^{\circ}$ anos que veio a ideia de focar em um objeto de estudo durante o bimestre: a Grécia antiga. Foram estudadas a teogonia grega, o mito do minotauro e as histórias relacionadas ao oráculo de Delfos.

Do lado da história, o professor abordou a formação histórica da cultura grega, abrangendo os principais reinos, o jogo de forças entre as dominações culturais da época, a estrutura social da Grécia antiga e também a história das ideias destes povos. Especialmente sobre o mito do minotauro, tendo como protagonista Teseu, filho de Zeus, os discentes puderam compreender a história por dois lados: o histórico-social, e o 
mítico. Enquanto na disciplina de história foi mostrado as invasões do rei Minos e sua dominação política das ilhas gregas, nas aulas de ER foi instigada a percepção de mito como expressão simbólica de um fato. Assim, paralelamente a um entendimento propriamente histórico das relações entre os povos da antiga Grécia, as aulas de ER tentaram mostrar como o mito do minotauro e Teseu evidencia a dominação do reino de Creta sobre os povos gregos através de uma linguagem simbólica, rica em metáforas, significados ambíguos e sagas heroicas.

A temática do mito do minotauro e a dominação cretense da Grécia foram debatidas em sala de aula, mas também foi cobrada em avaliações formativas através de exercícios em sala de aula. Os exercícios buscavam desenvolver a capacidade de interpretação da linguagem simbólica presente nos mitos. Um exemplo de questão trabalhada em sala de aula foi: "O que o tributo dos sete rapazes e sete moças representa na história?", nessa questão, o educando deve compreender a metáfora dos 14 jovens no labirinto do minotauro como um símbolo da dominação do rei Minos sobre os gregos. Nas avaliações bimestrais, foram utilizadas questões com a mesma lógica para a teogonia grega e o oráculo de Delfos.

No entanto, o estudo sobre o mundo grego antigo não parou por aqui: como foi dito, estudamos a teogonia grega, e depois o oráculo de Delfos. Obsevei durante as aulas que os estudantes apresentaram uma facilidade de compreender o mundo grego, inclusive seus mitos e estruturas religiosas. Por vezes, o presente professor teve que estudar mais do que o conteúdo exigia, para responder a dúvidas inquietantes dos estudantes, relativas as genealogias dos deuses, datas de acontecimentos ou explicações sobre histórias antigas dos gregos, muitas vezes trazidas por eles mesmos. Devido a esse interesse e facilidade com o conteúdo trabalhado, percebi um desenvolvimento cognitivo mais rápido, eficiente, além de aprofundamentos na interpretação da linguagem simbólica.

Acredito que esses bons resultados tem como principal causa o trabalho interdisciplinar desenvolvido entre o professor de História e o de ER (eu) dos $6^{\circ}$ anos. A interação entre o estudo histórico da Grécia antiga e uma leitura interpretativa dos seus mitos enquanto expressão sociocultural proporcionou o desenvolvimento cognitivo de grande parte dos estudantes, que apresentaram notas elevadas em sua maioria: dos 105 estudantes do três $6^{\circ}$ anos, 53 apresentaram nota " $A$ " 
(muito acima da média), 24 apresentaram nota "B" (na média ou pouco acima) e somente 28 reprovados com a nota "C". Mesmo com um número significativo de reprovação, mais da metade dos estudantes mostraram rendimento acima da média, evidenciando que foram desenvolvidas habilidades e capacidades interpretativas de modo satisfatório, contribuindo para a formação cidadã dos educandos.

\section{À guisa de conclusão - a busca pela legitimidade do ER}

Será discutido agora como os trabalhos interdisciplinares no ambiente da escola pública e laica podem fomentar, dentre outras coisas, um status de legitimidade do ER neste espaço. Como foi apontado anteriormente, existe um descaso em relação ao ER nas escolas públicas brasileiras, assim como em Minas Gerais, onde ocorreram as experiências pedagógicas relatadas. Para dar mais um exemplo de como o ER é tratado de forma negativamente diferenciada dentro das escolas públicas, citamos uma indagação que ocorreu frequentemente, por parte de toda comunidade escolar, quando um estudante foi reprovado em ER: "Como você conseguiu tomar recuperação em ER?".

A situação citada acima demonstra o status negativo e depreciado em que o ER se encontra. Temos duas hipóteses, inspirada no sociólogo Antônio Flavio Pierucci (1999) e na discussão de Diniz (2010) sobre a crença social na anterioridade do fato religioso na sociedade brasileira. A hipótese é que as antigas aulas de ER - que na prática nada mais eram do que uma catequese dentro da escola pública e que ainda hoje persevera de forma branda - fabricaram um status desqualificado de ER. Uma segunda hipótese é que essa desqualificação ecoa dentro do ambiente escolar, por vezes, sob uma falsa legitimidade de algo necessário, já que a religião (cristã) seria algo necessário à vida. Nessa segunda hipótese, o ER seria superficialmente legitimado na escola pública, mas teria um caráter de disciplina não acadêmica vinculada a alguma tradição religiosa. Já que não é vista como algo acadêmico, nem fruto de um saber científico, seu conteúdo não apresentaria nenhum desafio cognitivo aos estudantes, sendo moralmente obrigatório o discente ser aprovado, sem necessidade que bom desempenho.

Consideremos então a (possível) veracidade dessas hipóteses a partir da bibliografia sobre ER e da experiência docente relatada. De forma que tais situações 
possam ser superadas, propomos como método norteador para o ER a interdisciplinaridade. Esse método é uma ferramenta de legitimação dessa disciplina no ambiente das escolas públicas e laicas. Listamos como resultados positivos desse método: 1) interação com demais professores, possibilitando a divulgação do novo modelo de ER e fomentando a interdisciplinaridade na escola; 2) facilidade no processo ensino/aprendizagem pelos estudantes: os estudantes apresentam maior facilidade de compreensão das temáticas da Ciência da Religião, além de um maior desenvolvimento cognitivo; 3) legitimação do ER através da desmitificação do que é a disciplina e quais são seus objetivos e contribuições a uma formação cidadã e laica aos educandos.

Mas a legitimação do ER não deve acontecer somente dentro do ambiente escolar, mas também o poder público através das secretarias de educação deve estar cientes do potencial do ER para a educação. O histórico de descaso dos governos com a disciplina denuncia a falta de valor que o ER tem no Brasil e em Minas Gerais. Se, por outro lado, for demonstrado que o ER pode ser um motor para a prática interdisciplinar nas escolas públicas, essa disciplina pode mudar seu status de uma catequese sem fins cognitivos para uma fomentadora da prática interdisciplinar nas escolas.

Se o ER tem um caráter interdisciplinar, antes de tudo o ER também apresenta conteúdos e objetivos próprios das disciplinas acadêmicas em que se baseia. Lembremos que se trata de uma transposição didática da Ciência da Religião. Ora, a Ciência da Religião, enquanto uma Ciência Cultural (Hock, 2010), abarca todo um leque de disciplinas como sociologia, etnologia, antropologia, psicologia, direito, filologia, história cultural, geopolítica, e até mesmo as chamadas etnociências. Sendo assim, o ER também pode ser visto como uma iniciação à antropologia cultural e a sociologia no ensino fundamental; ou ainda como uma transposição didática de disciplinas que (ainda) não estão presentes nas escolas, como psicologia ou direito.

\section{Referenciais}

BIACA, Valmir et al. O sagrado no ensino religioso / Valmir Biaca; Elson Oliveira Souza; Emerli Scholgl; Sérgio Rogério Azevedo Junqueira [e] Sant'Ana, René Simonato (Cadernos pedagógicos do ensino fundamental, v.8). Curitiba: SEED Paraná, 2006.

CARON, Lurdes (org.). O ensino religioso na nova LDB; histórico, exigências, documentário. Petrópolis: Vozes, 1997. 
DANTAS, Douglas Cabral. O ENSINO RELIGIOSO NA REDE PÚBLICA ESTADUAL DE BELO HORIZONTE, MG: história, modelos e percepções de professores sobre formação e docência. Mestrado em Educação. PUC-MG, 2002.

DINIZ, Debora; LIONÇO, Tatiana; CARRIÃO, Vanessa. Laicidade e ensino religioso no Brasil. Brasília: UNESCO: LetrasLivres: EdUnB, 2010.

DURAND, Gilbert. As Estruturas Antropológicas do Imaginário. São Paulo, Martins Fontes, 2002.

DURKHEIM, Émile. As Formas Elementares da Vida Religiosa: o sistema totêmico na Austrália. São Paulo: Martins Fontes, 1996.

FIGUEIREDO, Anísia de Paula. Realidade, poder, ilusão. Um estudo sobre a legalização do ensino religioso nas escolas e suas relações conflitivas como disciplina sui generis no interior do sistema público de ensino. Mestrado em Ciências da Religião. PUC-SP, 1999.

FÓRUM NACIONAL PERMANENTE DO ENSINO RELIGIOSO (FONAPER). Parâmetros curriculares nacionais - ensino religioso. São Paulo: Mundo Mirim, 2009.

HOCK, Klaus. Introdução à ciência da religião. São Paulo: Edições Loyola, 2010.

JUNQUEIRA, Sérgio R. Azevedo. O processo de escolarização do Ensino Religioso no Brasil. Petrópolis, Vozes, 2002.

JUNQUEIRA, Sérgio R. Azevedo. A construção histórica entre o Ensino Religioso e as Ciências da Religião no cenário brasileiro. Em OLIVEIRA, Pedro A. Ribeiro; MORI, Geraldo de, (orgs.). Religião e educação para a cidadania. São Paulo: Paulinas; Belo Horizonte: Soter, 2011.

PIERUCCI, Antônio Flavio. Sociologia da Religião: área impuramente acadêmica. In MICELI, Sérgio (org). O que ler na ciência social brasileira (1970-1995). v.2. São Paulo: Sumaré, Anpocs/Capes, 1999.

POLIDORO, Lurdes de Fátima e STIGAR, Robson. A Transposição Didática: a passagem do saber científico para o saber escolar. Ciberteologia Revista de Teologia \& Cultura, Edição no 27 - Ano VI - Janeiro/Fevereiro, 2010. Disponível em http://ciberteologia.paulinas.org.br/ciberteologia/index.php/notas/a-transposicaodidatica-a-passagem-do-saber-cientifico-para-o-saber-escolar/. Acessado em 26/06/2013.

POMBO, Olga. Interdisciplinaridade e Integração dos Saberes. Liinc em Revista, v.1, n.1, março, 2005. 
SECRETARIA ESTADUAL DE EDUCAÇÃO DE MINAS GERAIS. Guia de orientação curricular, conteúdos básicos (versão preliminar). Projeto de Aceleração de Aprendizagem - Acelerar para vencer (PAV). SEE-MG: 2009.

SECRETARIA DE ESTADO DE EDUCAÇÃO DE MINAS GERAIS. Conteúdo Básico Comum - História. Educação Básica - Ensino Fundamental (5a a 8a séries). SEE-MG: 2006

SECRETARIA DE ESTADO DE EDUCAÇÃO DE MINAS GERAIS. Conteúdo Básico Comum - Ciências. Educação Básica - Ensino Fundamental (5a a 8a séries). SEE-MG: 2006

SECRETARIA DE ESTADO DE EDUCAÇÃO DO PARANÁ. Diretrizes Curriculares da Educação Básica - Ensino Religioso. SEED-PR: 2008.

SIQUEIRA, Giseli do Prado. Tensões entre duas propostas de ensino religioso, estudo do fenômeno religioso e/ou educação da religiosidade. Mestrado em Ciências da Religião, PUC-SP, 2003.

USARSKI, Frank. Constituintes da ciência da religião; cinco ensaios em prol de uma disciplina autônoma. São Paulo: Paulinas, 2006.

USARSKI, Frank (org.). O espectro disciplinar da ciência da religião. São Paulo: Paulinas, 2007.

VIANNA, Rejane P. Marta; COSTA, Matheus Oliva da; CRUZ, Jéssica Dayanna Vieira da; SILVA, Nilva Elisabete Gomes; RODRIGUES, Weslley Wallce. A percepção de educandos (Crianças e Adolescentes) sobre a Educação Religiosa em escolas da educação básica do Norte de Minas. Anais do $24^{\circ}$ Congresso Internacional da Sociedade de Teologia e Ciências da Religião - SOTER, 2011. Disponível em http://ciberteologia.paulinas.org.br/ciberteologia/index.php/livros-digitais/. Acessado em 26/06/2013.

Recebido: $25 / 06 / 2013$

Received: 06/25/2013

Aprovado: 04/07/2013

Approved: 07/04/2013 